\title{
Serotonin Potentiates Transforming Growth Factor-beta3 Induced Biomechanical Remodeling in Avian Embryonic Atrioventricular Valves
}

\author{
Philip R. Buskohl ${ }^{1}$, Michelle L. Sun ${ }^{2}$, Robert P. Thompson ${ }^{3}$, Jonathan T. Butcher ${ }^{2 *}$ \\ 1 Department of Mechanical and Aerospace Engineering, Cornell University, Ithaca, New York, United States of America, 2 Department of Biomedical Engineering, Cornell \\ University, Ithaca, New York, United States of America, 3 Department of Cell Biology and Regenerative Medicine, Medical University of South Carolina, Charleston, South \\ Carolina, United States of America
}

\begin{abstract}
Embryonic heart valve primordia (cushions) maintain unidirectional blood flow during development despite an increasingly demanding mechanical environment. Recent studies demonstrate that atrioventricular (AV) cushions stiffen over gestation, but the molecular mechanisms of this process are unknown. Transforming growth factor-beta (TGF $\beta$ ) and serotonin (5-HT) signaling modulate tissue biomechanics of postnatal valves, but less is known of their role in the biomechanical remodeling of embryonic valves. In this study, we demonstrate that exogenous TGF $\beta 3$ increases AV cushion biomechanical stiffness and residual stress, but paradoxically reduces matrix compaction. We then show that TGF $\beta 3$ induces contractile gene expression (RhoA, aSMA) and extracellular matrix expression (col1 $\alpha 2)$ in cushion mesenchyme, while simultaneously stimulating a twofold increase in proliferation. Local compaction increased due to an elevated contractile phenotype, but global compaction appeared reduced due to proliferation and ECM synthesis. Blockade of TGF $\beta$ type I receptors via SB431542 inhibited the TGF $\beta 3$ effects. We next showed that exogenous 5 -HT does not influence cushion stiffness by itself, but synergistically increases cushion stiffness with TGF $\beta 3$ co-treatment. 5-HT increased TGF $\beta 3$ gene expression and also potentiated TGF $\beta 3$ induced gene expression in a dose-dependent manner. Blockade of the 5HT2b receptor, but not 5-HT2a receptor or serotonin transporter (SERT), resulted in complete cessation of TGF $\beta 3$ induced mechanical strengthening. Finally, systemic 5-HT administration in ovo induced cushion remodeling related defects, including thinned/atretic AV valves, ventricular septal defects, and outflow rotation defects. Elevated 5-HT in ovo resulted in elevated remodeling gene expression and increased TGF $\beta$ signaling activity, supporting our ex-vivo findings. Collectively, these results highlight TGF $\beta / 5-\mathrm{HT}$ signaling as a potent mechanism for control of biomechanical remodeling of AV cushions during development.
\end{abstract}

Citation: Buskohl PR, Sun ML, Thompson RP, Butcher JT (2012) Serotonin Potentiates Transforming Growth Factor-beta3 Induced Biomechanical Remodeling in Avian Embryonic Atrioventricular Valves. PLoS ONE 7(8): e42527. doi:10.1371/journal.pone.0042527

Editor: Michael Schubert, Ecole Normale Supérieure de Lyon, France

Received January 23, 2012; Accepted July 9, 2012; Published August 6, 2012

Copyright: ( $) 2012$ Buskohl et al. This is an open-access article distributed under the terms of the Creative Commons Attribution License, which permits unrestricted use, distribution, and reproduction in any medium, provided the original author and source are credited.

Funding: This project was funded by the American Heart Association (0830384N, JTB; www.heart.org), National Institutes of Health (HL110328, JTB; HL91452, RPT; www.NIH.gov), The Hartwell Foundation (JTB; www.thehartwellfoundation.org) and the National Science Foundation (CBET-0955172, JTB; DGE0841291, PRB; www.nsf.gov). The funders had no role in study design, data collection and analysis, decision to publish, or preparation of the manuscript.

Competing Interests: The authors have declared that no competing interests exist.

*E-mail: jtb47@cornell.edu

\section{Introduction}

Biomechanical remodeling is the process by which living tissues reorganize, reshape, and refit their microstructure in adaptation to changing internal and external forces. This process defines much of embryogenesis, during which initially indistinct cellular masses acquire shape and functional specificity through production and manipulation of the extracellular matrix (ECM). This is particularly important for the morphogenesis of the heart, which is critically responsible for distributing nutrients as the embryo grows. The heart transitions rapidly from a tubular structure into a multi-chambered pumping organ, simultaneously growing over 100 -fold in volume [1]. The hemodynamic environment inside the heart increases dramatically in severity during this process [2-4], which means the biomechanical properties of the forming valves must be precisely tuned to maintain efficient unidirectional blood flow. Atrioventricular (AV) valve morphogenesis is characterized by rapid ECM accretion and turnover [5,6], which is hypothesized to be stimulated by a dynamic interaction of molecular and mechanical signaling. While numerous molecular agents important for valve morphogenesis have been identified [7-10], less is known about how these signals affect valve mechanics, which is a key readout of valve function.

The transforming growth factor-beta (TGF $\beta$ ) superfamily is critically important for a wide range of cellular processes [11-13], and is heavily involved in directing morphogenesis of AV cushions [14-18]. In the chick, TGF $\beta 2$ and TGF $\beta 3$ isoforms are necessary for the endothelial to mesenchymal transition (EMT) which initiates AV cushion development [19]. TGF $\beta 2$ induces initial cellcell separation of valve endothelial cells, while TGF $\beta 3$ stimulates their invasion and subsequent mesenchymal phenotype shift $[15,16]$. During post-EMT, these mesenchymal cells facilitate a transition in the cushion microstructure from glycosaminoglycans (GAGs) (hyaluronan, versican) toward fibrous structural proteins (collagen I, IV, V, fibronectin, periostin) [5,20,21]. This shift in ECM content translates into increased valve stiffness [22], and coincides with elevated expression of TGF $\beta 3$ in the cushions and AV canal [23]. Furthermore, TGF $\beta 3$ upregulates collagen I and 
periostin in post-EMT AV cushion explants [24], suggesting that TGF $\beta 3$ is a key modulator of cushion ECM content, and consequent mechanical properties. An aim of this study is to better understand this remodeling potential of TGF $\beta 3$ through a combined analysis of cushion stiffness, matrix compaction, cell proliferation, and ECM synthesis.

The capacity of TGF $\beta 3$ to stimulate valvular remodeling events underscores the importance of identifying molecular signals which modulate TGF $\beta$ activity. Recent studies indicate that serotonin (5HT) interacts with TGF $\beta$ signaling in adult heart valves $[25,26]$, and can also alter valve mechanical properties [27,28]. 5-HT, which is a monoamine neurotransmitter derived from the essential amino acid tryptophan [29], increased the stiffness of porcine aortic valve cusps with the endothelial layer denuded [27], and under cyclic stretch [30]. Serotonin also increased collagen synthesis in human and sheep valve interstitial cells (VICs) [25,31]. Reports in adult VICs indicate that 5-HT can upregulate TGF $\beta$, resulting in cell differentiation and aberrant connective tissue accumulation $[25,26,32]$. In development, serotonin is active in key events such as cardiac progenitor patterning, left-right laterality, and migration of the neural crest [33-37]. Murine AV cushions express the serotonin receptors 5-HT2a and 5-HT2b, and the serotonin transporter (SERT) by the completion of EMT [38,39], which is when TGF $\beta 3$ expression increases in the cushions $[18,40]$. Latent TGF $\beta$ binding protein and serotonin binding protein are also expressed in murine post-EMT endocardial cushions $[41,42]$, highlighting each pathway's capacity to regulate expression of their ligands. The proximity of these TGF $\beta$ and 5-HT signaling components suggests that they may be interacting partners in post-EMT cushion development. Furthermore, a recent study reported TGF $\beta 1$ upregulation in murine SERT KO hearts at near fetal stages, which was hypothesized to be a consequence of excess 5-HT signaling due to SERT inhibition [43]. In light of these signaling interactions in both adult and development models, we hypothesize that this mechanically relevant crosstalk of TGF $\beta$ and 5-HT may play a role in modulating embryonic AV cushion biomechanics.

The objectives of this study therefore were to characterize the remodeling capacity of TGF $\beta 3$ in $\mathrm{AV}$ cushions, and determine how TGF $\beta 3$ and 5-HT may act together to regulate cushion biomechanical remodeling. Chick AV cushion biomechanics, compaction, and candidate gene expression were quantified through implementation of an ex vivo cushion culture system. We determined that TGF $\beta 3$ induces $\mathrm{AV}$ valve stiffening through increases in cell proliferation, myofibroblastic differentiation, and collagen synthesis. 5-HT enhances the AV valve stiffening effect of TGF $\beta 3$ in a dose-dependent manner. Crosstalk between TGF $\beta 3$ and 5-HT signaling was investigated via molecular inhibition studies. The ex vivo results were then tested in ovo through an elevated 5-HT model. These results suggest that 5-HT may be an important potentiator of TGF $\beta 3$ signaling in embryonic valve morphogenesis and biomechanical stiffening.

\section{Materials and Methods}

\section{Ethics Statement}

Leghorn avian embryos from Hamburger-Hamilton stages (HH) 17-36 were utilized in this research. All procedures in this study followed the guidelines of Cornell University and $\mathrm{NIH}$ policy, which state that avian embryos of these stages are not considered vertebrate animals for the purposes of IACUC regulation.

\section{AV cushion remodeling organ culture model}

Fertilized leghorn chicken eggs were incubated until stage HH25 (Day 4.5). The AV cushions were isolated from their myocardial attachment in ice-cold sterile Earle's Balanced Salt Solution (EBSS; Quality Biological, Inc.). Single cushions were cultured in $20 \mu \mathrm{L}$ hanging drops for 24 hours at $38^{\circ} \mathrm{C}$ in a $5 \%$ $\mathrm{CO}_{2}$ environment. Control culture media consisted of Medium 199 (M199 w/phenol red and L-glutamine; Gibco) with 1\% concentrations of penicillin/streptomycin (Gibco), Insulin-Transferrin-Selenium (ITS, Gibco), and chick serum (Gibco). For experiments, control media was treated with one or more of the following reagents: human recombinant TGF 33 ( $1 \mathrm{ng} / \mathrm{ml}$, Sigma), serotonin hydrochloride $(0.47-47 \mu \mathrm{M}$, Sigma), Cytochalasin D (1 $\mu \mathrm{M}$, Sigma), 5-HT2a inhibitor MDL100,907 (0.01-1 $\mu \mathrm{M}$, Axon Medchem BV), 5-HT2b inhibitor SB204741 (0.35-35 $\mu \mathrm{M}$, Sigma), SERT inhibitor Fluoxetine (1-10 $\mu \mathrm{M}$, Sigma) and Alk 4,5,\&7 inhibitor SB431542 hydrate (0.26-26 $\mu \mathrm{M}$, Sigma). TGF $\beta 3$ was reconstituted in $4 \mathrm{mM} \mathrm{HCl}$ solution containing $1 \mathrm{mg} / \mathrm{ml}$ BSA, all other reagents were dissolved in DMSO. The $470 \mathrm{nM} \mathrm{5-}$ HT dose was considered physiological, based on HPLC measured concentrations in $10 \%$ fetal bovine serum media $(\sim 100 \mathrm{nM}[44])$. The $47 \mu \mathrm{M} 5$-HT dosage is similar to prior in vitro/ex vivo studies in postnatal valves $[25,27,28,30,45]$, so we conservatively considered this dose high for our studies.

\section{Micromechanical testing}

Cushion mechanical properties were measured after 24 hour treatment in the ex vivo study and at $\mathrm{HH} 25$ in the in ovo study using the micromechanical pipette aspiration technique [22,46,47]. A glass micropipette $(\sim 70-100 \mu \mathrm{m}$ in diameter $)$ was placed adjacent to the cushion surface, and a small vacuum pressure was incrementally applied. The pressure source was a $200 \mu \mathrm{L}$ pipetter calibrated with a custom manometer. Previous strain history was mitigated by preconditioning with $\sim 20$ cycles of low pressurization $(<1 \mathrm{~Pa})$. The tissue was then monotonically loaded with increasing static pressure loads, at which images were captured. Aspirated length L, measured as the length from the tip of the pipette to tip of the tissue furthest inside the pipette, was converted into an experimental "stretch ratio", $\lambda=\frac{L+r_{p}}{r_{p}}$, by normalizing to the pipette radius, $r_{p}$. The cushion was assumed to be an isotropic, incompressible, hyperelastic material with an exponential free energy law, $W=\frac{C}{2}\left\{\exp \left[\alpha\left(I_{B}-3\right)\right]-1\right\}$, where $\mathrm{I}_{\mathrm{B}}$ is the first invariant of left Cauchy Green stretch tensor. AV cushion material isotropy at HH25 was supported by a lack of preferred matrix orientation as determined by ubiquitous protein stain 5-DTAF (50 $\mu \mathrm{M}$ Invitrogen; Figure $\mathrm{S} 1$ ). The $\Delta \mathrm{P}$ vs. $\lambda$ data was then fit to the axial stress equation of a uni-axially loaded bar of this exponential material, specifically, $\sigma_{\text {axial }}=\alpha C \exp \left[\alpha\left(\lambda^{2}+\frac{2}{\lambda}-3\right)\right]$ $\left(\lambda^{2}-\frac{1}{\lambda}\right)$. From previous analysis [22], the $\Delta \mathrm{P}$ vs. $\lambda$ curve differs from the uniaxial load expression by a scale factor, $\gamma$. This scale factor was numerically determined to be a function of only the material parameter $\alpha$. Due to the nonlinear nature of the data, the mechanical testing data is presented as strain energy density. This was calculated as the area under the $\Delta \mathrm{P}$ vs. $\lambda$ curve fit from $\lambda=1-$ 2 (Figure 1A), which from our assumed material model is $W_{1-2}=\frac{C^{*}}{2}\{\exp (2 \alpha)-1\}$, where $\mathrm{C}^{*}=\gamma \mathrm{C}$.

\section{Compaction \& Opening Angle Assays}

Compaction of the AV cushions was quantified as the ratio of cross-sectional area before $\left(A_{0}\right)$ and after (A) 24 hours of culture in 

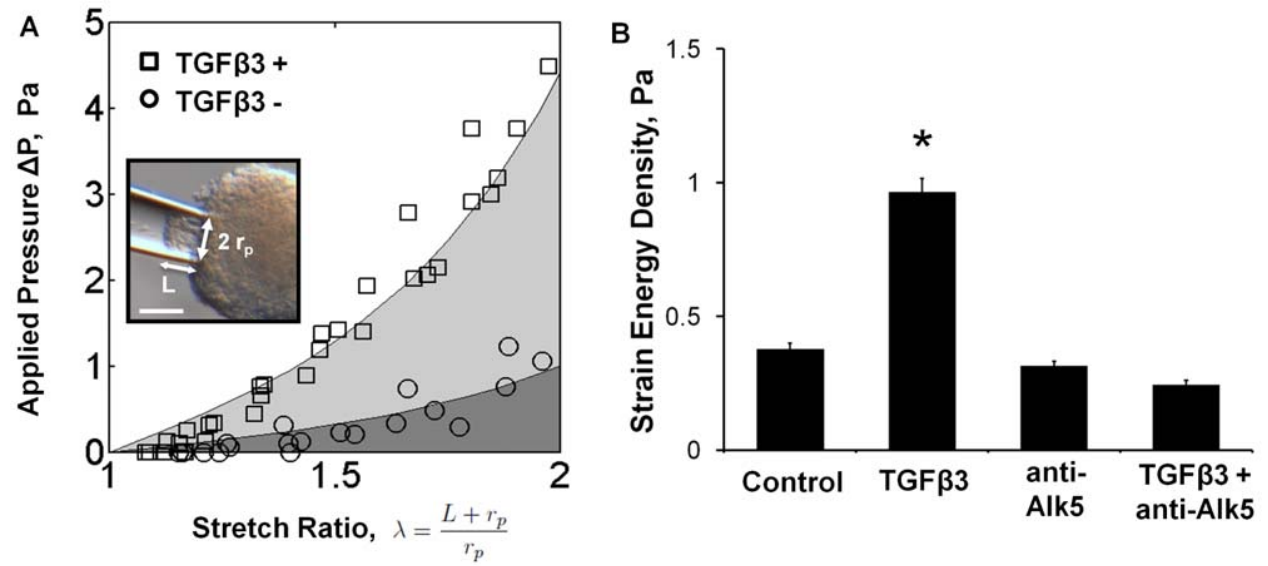

Figure 1. TGF $\beta 3$ treatment increases stiffness of AV cushions through Alk5 mediated pathway. A) Representative pipette test data for TGF $\beta 3$ ( $1 \mathrm{ng} / \mathrm{ml}$, TGF $\beta 3+)$ and control media (TGF $\beta 3-$ ) treated cushions, $\mathrm{n}=4$. Strain energy density was calculated from the shaded regions beneath the $\Delta \mathrm{P}$ vs $\lambda$ curves. Inset: image of aspirated HH25 AV cushion after 24 hours of culture. The pipette radius, $r_{p}$, and the aspirated length, $\mathrm{L}$ are indicated. Scale bar $=70 \mu \mathrm{m}$. B) AV cushion strain energy density increased with TGF $\beta 3$ treatment, but was blocked by Alk5 inhibition (SB431542, $2.6 \mu \mathrm{M})$. mean \pm SEM, $n \geq 7,{ }^{*} \mathrm{p}<0.0001,2$-way ANOVA.

doi:10.1371/journal.pone.0042527.g001

the different treatment conditions, denoted $\mathrm{A} / \mathrm{A}_{0}$. This ratio measures the combined biomechanical remodeling effects of cell traction, proliferation, and ECM synthesis. To isolate cell traction effects, we quantified the opening angles created by micro-slit incision in AV cushions after 24 hours of treatment. The incision was made along the centerline of the spherical cushion mass, extending approximately one radius into the cushion, and immediately created a pie-wedge with defined opening angle. Opening angles are an established indicator of tissue residual stress [48], which is primarily a function of cell traction forces in our culture system. Images were taken at $150 \times$ magnification using Zeiss Discovery v20 stereomicroscope (Spectra Services, Inc.) and QImaging Retiga 4000R Fast camera (Spectra Services, Inc). Cross-sectional area and opening angle were measured from calibrated images using NIH ImageJ image analysis software.

\section{Immunohistochemistry (IHC)}

Proliferation was assessed through bromodeoxyuridine (BrdU) incorporation into HH25 AV cushion hanging drops. BrdU reagent (Invitrogen) was added at 1:100 dilution in culture medium 6 hours prior to completion of 24 hour culture. AV cushions were then rinsed and fixed in $4 \%$ paraformeldehyde (PFA). BrdU incorporation was assessed via immunofluorescent antibody staining and confocal microscopy using anti-BrdU 488 (1:100, Invitrogen), with DRAQ5 (1:1000, Biostatus) as a DNA counterstain. Images were processed via Image $J$, and BrdU incorporation was quantified as the ratio of BrdU positive cells to total cell count. IHC was also used to label phosphorylated Smad2/3 (pSmad2/3) complex in HH25 cushions isolated from the systemic 5-HT in ovo model. Isolated cushions were fixed in $4 \%$ PFA and then stained via standard whole mount IHC protocol. The cushions were stained with primary $\mathrm{pSmad} 2 / 3$ polyclonal goat anti-human antibody (1:50, Santa Cruz) followed with 488 fluorescent secondary (1:100, Santa Cruz) and cell nuclei counter stain DRAQ5 (1:1000). pSmad2/3 was quantified as the number of cell nuclei with localized $\mathrm{pSmad} 2 / 3$ divided by the total number of cell nuclei.

\section{PCR quantification of gene expression}

At the end of 24 hour treatment, AV cushion mRNA was isolated and purified using RNEasy Isolation Kit (Qiagen). A set of 8-10 cushions were pooled per test sample. RNA integrity was determined by NanoDrop spectrometry, using A260/A280 ratio between 1.8 and 2.2 as quality control. cDNA synthesis was completed using SuperScript III first strand RT-PCR kit (Invitrogen) with oligo(dT) primers. Amplification reactions were as follows: $\left(95^{\circ} \mathrm{C} 15 \mathrm{~s}\right),\left(54^{\circ} \mathrm{C} 15 \mathrm{~s}\right),\left(72^{\circ} \mathrm{C} 30 \mathrm{~s}\right)$. Power Syber Green (Applied Biosystems) replication indicator was read at the completion of each $72^{\circ} \mathrm{C}$ stage. Standard curves for all primers (listed in Table S1) were generated from HH34 brain mRNA and normalized to $18 \mathrm{~s}$ ribosomal RNA. Threshold cycle count, $\mathrm{G}(\mathrm{t})$, was used to calculate gene expression via the $\Delta \Delta \mathrm{Ct}$ method using $18 \mathrm{~s}$ rRNA as a housekeeping reference gene [49].

\section{5-HT administration in ovo}

HH17 stage fertilized leghorn chicken eggs were windowed on their blunt side. Up to $1.0 \mathrm{mg}$ of serotonin (Sigma) was diluted into $100 \mu \mathrm{L}$ of PBS and dispensed directly onto the chorionic membrane at $\mathrm{HH} 17, \mathrm{HH} 25$, or HH31. The max 5-HT dosage was equivalent to $18 \mathrm{mg} / \mathrm{kg}$ which is comparable to other elevated 5 -HT animal models $(25 \mathrm{mg} / \mathrm{kg}$ and $75 \mathrm{mg} / \mathrm{kg}$ ) [50,51]. After 5HT treatment, chicks were then sealed and cultured at $55 \%$ humidity and $38^{\circ} \mathrm{C}$ until HH36 (Day 10). Preliminary experiments demonstrated that 5-HT treatment sometimes resulted in an ectopic heart, so additional embryos were alternatively subjected to a thoracotomy that mimicked an ectopic heart without serotonin administration as a control. Embryos were then dissected and analyzed for gross anatomical defects. Hearts with intact great artery connections were then removed, cleared, and analyzed with $3 \mathrm{D}$ confocal microscopy or serial section histology using Movat's pentachrome stain. Optical fluorescence tomography (OFT) of ventricular, valve, and outflow vessel anatomy was performed as previously described [52,53]. Briefly, HH36 hearts were freshly isolated and rinsed with $1 \%$ lidocaine in PBS buffer. Following rinse, hearts were perfused with fluorescein isothiocyanate-poly-L-lysine (Sigma) via micro injection and then fixed in $4 \%$ PFA. The poly-L-lysine binds to the negatively charged endothelial glycocalyx. Hearts were then cleared using Murray's 
Clear, followed by deep tissue 3D imaging via fluorescence confocal microscopy. Hearts were screened for major defects, and valve morphometry were quantified from this using ImageJ. Valve measurements included leaflet length, average thickness, and minimal thickness with control $n=3$ and 5-HT treatment $n=6$. Average thickness $\left(t_{\text {avg }}\right)$ was calculated as $t_{\text {avg }}=A_{L} / L$, where $L$ is the annulus-tip length of the leaflet, and $\mathrm{A}_{\mathrm{L}}$ is cross-sectional area of leaflet. The location of minimum thickness was generally the same for all specimens regardless of treatment.

\section{Statistical Analyses}

All data is presented as mean \pm standard error of the mean for the number of samples reported. Statistical comparisons between groups were performed using ANOVA for data sets involving more than two groups, or two-tailed test when only two groups were compared. Defect prevalence in the in ovo model was compared using a chi-squared statistical test. In all comparisons, differences between groups was considered statistically significant for $\mathrm{p}$ valves smaller than 0.05 .

\section{Results}

\section{TGF $\beta 3$ increases AV cushion stiffness}

Ex vivo cultured AV cushions exhibited nonlinear mechanical behavior that was well described by the exponential constitutive model (Figure 1A). Administration of exogenous TGF $33(1 \mathrm{ng} / \mathrm{ml})$ increased cushion stiffness 2.5 fold over controls $\left(\mathrm{W}_{\text {TGF } 33}=0.965 \pm 0.051\right.$ vs. $\quad \mathrm{W}_{\text {Contr }}=0.378 \pm 0.021, \quad \mathrm{p}<0.0001$ Figure 1B). Inhibition of canonical TGF $\beta$ signaling via the TGF $\beta$ type 1 receptor Alk $5(2.6 \mu \mathrm{M}$ SB431542 [54]) blocked the increase in cushion stiffness $\left(\mathrm{W}_{\mathrm{T}+\mathrm{TI}}=0.245 \pm 0.043\right.$ Figure 1B). The Alk5 inhibitor alone had no effect on cushion biomechanics. TGF $\beta 3$-treated cushions compacted less than controls, with compaction quantified as the ratio of cross-sectional area before and after treatment $\left(\mathrm{A} / \mathrm{A}_{0}=0.925 \pm 0.028\right.$ vs. A/ $\mathrm{A}_{0}=0.508 \pm 0.017, \mathrm{p}<0.0001$ Figure $\left.2 \mathrm{~A}\right)$. This was unexpected because the Cytochalasin $\mathrm{D}(\mathrm{CytD}, 1 \mu \mathrm{M})$ results suggested that compaction and stiffness are directly related. CytD inhibited cytoskeletal actin polymerization which resulted in a 5.3 fold decrease in strain energy density of the $\mathrm{AV}$ cushions relative to control $\left(\mathrm{W}_{\mathrm{CytD}}=0.072 \pm 0.016\right.$, Figure $\left.\mathrm{S} 2 \mathrm{~A}\right)$. Without actin polymerization the AV cushion cells did not compact the matrix, and the cushion did not remodel into the spherical configuration observed in all other treatments. Instead, the post-treatment cushion area was significantly larger than initial area, suggesting a relaxation of pre-treatment actin forces $\left(\mathrm{A} / \mathrm{A}_{0}=1.60 \pm 0.03\right.$, Figure S2B). The TGF $\beta 3$ results of stiffness increase with compaction decrease did not align with this trend. Alk5 inhibition did return compaction behavior to control levels (A/ $\mathrm{A}_{0}=0.570 \pm 0.035$ Figure S3), indicating that the stiffness and compaction results are both dependent on activation of canonical TGF $\beta 3$ signaling. To better understand the relationship between stiffness and compaction, cushion opening angles were quantified to approximate differences in cell traction forces. The opening angle of TGF $\beta 3$ cushions was 1.29 fold larger than controls $\left(74.6^{\circ} \pm 2.0^{\circ}\right.$ vs. $57.7^{\circ} \pm 1.4^{\circ}, \mathrm{p}<0.001$ Figure $\left.2 \mathrm{~B}\right)$, indicating that TGF $\beta 3$ treated cushions did indeed have higher cell traction forces. Together, these results demonstrate that TGF $\beta 3$ induces cushion stiffening through Alk5, but with a concurrent reduction in tissue compaction that suggests other processes are also affected.

\section{TGF $\beta 3$ increases AV cushion proliferation and mesenchymal phenotype}

Contractile phenotype markers $\alpha$ SMA and RhoA were significantly upregulated with TGF $\beta 3$ treatment, $5.3 \pm 0.4$ and $2.1 \pm 0.3$ fold ( \pm SEM) respectively (Figure $3 \mathrm{~A}$ ), suggesting that TGF $\beta 3$ induced residual tension is partially due to an increased migratory/contractile phenotype of resident cushion mesenchyme. TGF $\beta 3$ treatment also upregulated mRNA expression of coll $\alpha 2$ mRNA $(3.8 \pm 0.9, \mathrm{p}<0.05)$ and cyclin b2 (3.9 \pm 0.7 fold, $\mathrm{p}<0.05)$, indicative of increased collagen I synthesis and cell proliferation, respectively. BrdU incorporation confirmed that TGF $\beta 3$ increased cushion cell proliferation 2.26 \pm 0.36 fold over controls $(\mathrm{p}<0.0001$, Figure 3B). Collectively, these results strongly suggest that while TGF $\beta 3$ treated AV cushion mesenchyme are more migratory/ contractile, concomitant increases in cell proliferation and matrix synthesis work to counteract aggregate matrix compaction. This explains how the TGF $\beta 3$ treated cushions are biomechanically stiffer, but appear minimally compacted. Furthermore, TGF $\beta 3$ treatment increased TGF $\beta 3$ transcription $(2.2 \pm 0.6$ fold, $\mathrm{p}<0.05)$, indicating a potential positive feedback loop for TGF $\beta 3$ control of AV cushion biomechanical remodeling.

\section{5-HT potentiates TGF $\beta 3$ signaling through $5-\mathrm{HT} 2 \mathrm{~b}$ receptor}

The effect of 5-HT dose on biomechanical remodeling, independently and in combination with TGF $\beta 3$, was systematically evaluated through the stiffness and compaction metrics of the AV cushion organ culture system. 5-HT administration by itself had no statistically significant effect on cushion stiffness. Combined treatment of TGF $\beta 3$ with physiological 5-HT $(470 \mathrm{nM})$ increased $\mathrm{AV}$ cushion stiffness $\left(\mathrm{W}_{\mathrm{T}+5-\mathrm{HT}}=\right.$ $1.136 \pm 0.035)$, but high 5 -HT dose $(5-\mathrm{HT}+=47 \mu \mathrm{M})$ eliminated any TGF $\beta 3$ induced stiffening effect $\left(\mathrm{W}_{\mathrm{T}+5-\mathrm{HT}+}=0.457 \pm 0.025\right.$, Figure 4). Neither selective inhibition of the 5-HT2a (MDL100907 $10 \mathrm{nM}$ ), 5-HT2b (SB204741 $2.6 \mu \mathrm{M}$ ) receptors, nor the serotonin transporter SERT (Flouxetine $10 \mu \mathrm{M}$ ) alone affected cushion stiffness (Figure 4). Yet in combination with TGF $\beta 3$, the anti-5HT2b treatment completely blocked TGF $\beta 3$ dependent stiffness and compaction behavior (Figure $4 \&$ Figure S3). Inhibition of the 5-HT2a receptor or SERT had no measurable effect on TGFß3 induced cushion biomechanics. The compaction and stiffness changes induced by 5 -HT potentiated TGF $\beta 3$ followed the same trend of TGF $\beta 3$ treatment alone, with compaction decreasing as stiffness increased and vice versa (Figure $4 \&$ Figure S3). The additional stiffening effect of 5-HT with TGF 33 was also eliminated with Alk5 inhibition, as shown through the combined treatment of TGF $33+5-\mathrm{HT}+$ anti-Alk5 in Figure S4. This combined treatment generated a strain energy density similar to the TGF $33+$ anti-Alk5 treatment $(0.209 \pm 0.023 \mathrm{~Pa}$ vs $0.245 \pm 0.16 \mathrm{~Pa}$, respectively), and further supported that the effects of 5-HT signaling on $\mathrm{AV}$ valve remodeling is dependent on canonical TGF $\beta$ signaling. Together, these findings suggest that exogenous 5-HT acts through the 5-HT2b receptor to augment or impair TGF $\beta 3$ induced cushion stiffening and compaction in a dosedependent manner.

\section{5-HT modulates TGF $\beta 3$ regulation of AV cushion mesenchyme phenotype}

Exogenous 5-HT administration potentiated remodeling-relevant gene expression in organ cultured AV cushion mesenchyme. TGF $\beta 3$ mRNA transitioned from $1.9 \pm 0.1$ fold upregulation over controls at physiological 5-HT to $0.40 \pm 0.16$ downregulation at high 5-HT dose (Figure 5A). The physiological 5-HT dose had no 

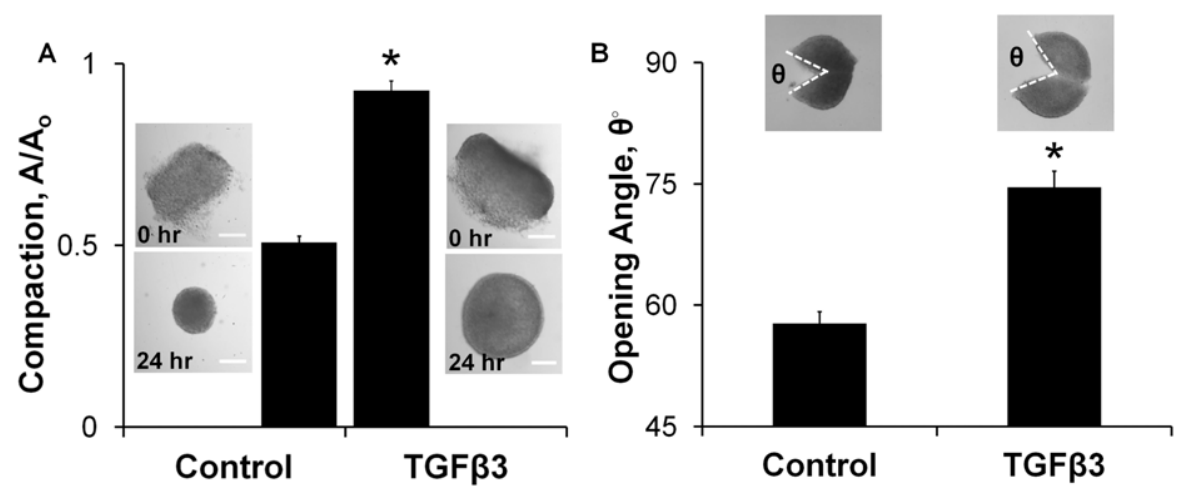

Figure 2. TGF $\beta 3$ treated cushions compact less than controls, but are under more residual tension. A) Bar graph of area ratios calculated from before and after images of 24 hour TGF $\beta 3$ treated cushions. Representative cushion images shown, scale bar $=100 \mu \mathrm{m}$. mean \pm SEM, $\mathrm{n} \geq 12$, ${ }^{*} \mathrm{p}<0.0001$, t-test B) Opening angle of 24 hour TGF $\beta 3$ treated cushions is greater than control, indicating tissue is under greater residual tension. Inset shows representative images with opening angle, $\theta$. mean \pm SEM, $n=10-11,{ }^{*} p<0.001$ t-test.

doi:10.1371/journal.pone.0042527.g002

statistically significant effect on $\alpha \mathrm{SMA}$, coll $\alpha 2$, cyclin b2, and RhoA expression. In contrast, high 5-HT significantly decreased transcription of $\alpha \mathrm{SMA}(0.18 \pm 0.09)$, collagen $1 \alpha 2(0.22 \pm 0.07)$, and RhoA $(0.46 \pm 0.11$ Figure $5 \mathrm{~A})$. No effect on cyclin b2 expression was observed at either dose, suggesting proliferation was not directly regulated by 5-HT. Physiological 5-HT did not affect TGF 33 induced gene expression (Figure $5 \mathrm{~B}$ ), but high dose 5-HT markedly reduced gene expression of TGF $\beta 3(0.86 \pm 0.20$ vs. $2.2 \pm 0.6), \alpha$ SMA (1.4 \pm 0.4 vs. $5.3 \pm 0.4)$, collagen $1 \alpha 2(1.3 \pm 0.3$ vs. $3.8 \pm 0.9$ ), and RhoA (1.3 \pm 0.2 vs. $2.1 \pm 0.3)$ (Figure 5B). Proliferation-related gene cyclin b2 was not significantly affected by 5 -HT in combination with TGF $\beta 3$. These results suggest that exogenous 5-HT potentiates TGF $\beta 3$ more likely through interaction with upstream activation points and/or TGF $\beta 3$ synthesis, rather than by interacting with TGF $\beta 3$ downstream targets directly.

We also analyzed the mRNA expression of intracellular 5-HT (i5-HT) related genes transglutaminase 2 (TGM2) and SERT. i5HT transamidates small GTPases and matrix proteins, in a process called "serotonylation" [44]. TGM2 is an i5-HT binding partner which assists transamidation of RhoA [55] and fibronectin [56], altering tissue mechanics through GTPase activation and matrix protein cross-linking, respectively. SERT mRNA expres- sion was significantly increased with 5 -HT treatment $(1.5 \pm 0.2$ fold, $\mathrm{p}<0.05)$, but was downregulated with the $5-\mathrm{HT}+$ dose $(0.46 \pm 0.12$ fold, Figure S5A). TGF 33 treatment stimulated a $4.0 \pm 1.0$ fold increase in TGM2, but SERT transcription remained near control levels $(0.70 \pm 0.11$, Figure S5B). Addition of 5-HT with TGF $\beta 3$ significantly decreased SERT and TGM2 mRNA, regardless of 5-HT dose. Although TGF $\beta 3$ treatment did upregulate TGM2, the downregulation of SERT by 5-HT treatment and the lack of mechanical changes seen with the SERT inhibitor suggest that serotonylation is not a primary mechanism of stiffness increase in the ex vivo culture remodeling results.

\section{Elevated 5-HT induces atrioventricular valvuloseptal defects in ovo}

As the effects of TGF $\beta$ signaling on valve formation are well studied $[17,18,57]$, we here test whether exogenous 5-HT administration in ovo alters valve morphogenesis. 5-HT administration in ovo at $\mathrm{HH} 17$ induced a spectrum of cardiac defects by HH36 (Day 10) as summarized in Table 1. Temporal and dosage dependant viability curves (Figure $\mathrm{S} 6 \mathrm{~A}$ ) showed that a $0.7 \mathrm{mg}$ dose
A

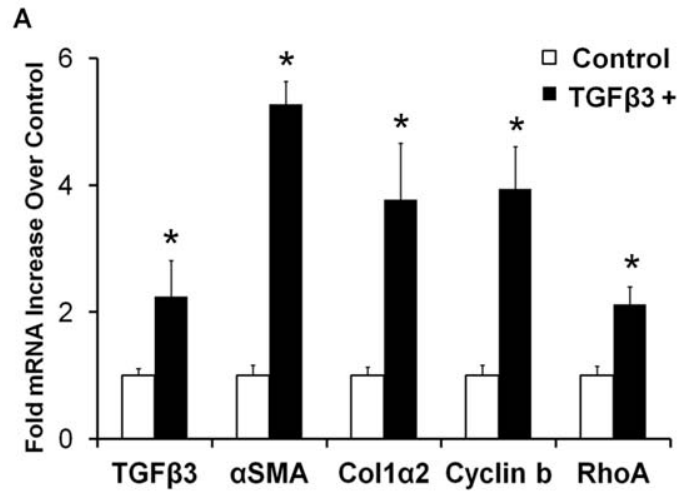

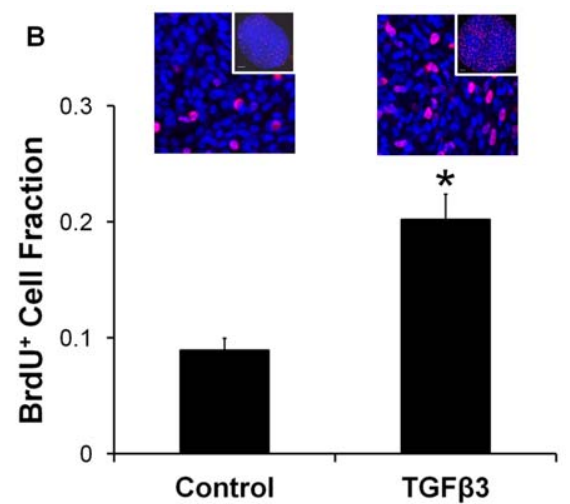

Figure 3. Remodeling behavior of TGF $\beta 3$ treated cushions is a balance of contractile differentiation, proliferation, and matrix synthesis. A) 24 hour TGF $\beta 3$ treated cushions upregulate contractile ( $\alpha S M A$, RhoA), proliferation (cyclin b), and extracellular matrix protein (col1 $\alpha 2$ ) encoding genes. TGF $\beta 3$ administration also significantly stimulated its own production. mean \pm SEM, $n=3-4$ pooled samples of 8-10 cushions, ${ }^{*} \mathrm{p}<0.05$, t-test. B) BrdU incorporation data (red) of TGF 33 treated cushions normalized to DRAQ5 cell nuclei counter stain (blue). BrdU was administered 6 hours prior to completion of 24 hour treatment. Representative confocal images are shown above each bar, with a global view of cushion contained in the inset. mean \pm SEM, $n=12,{ }^{*} p<0.0001$, t-test.

doi:10.1371/journal.pone.0042527.g003 


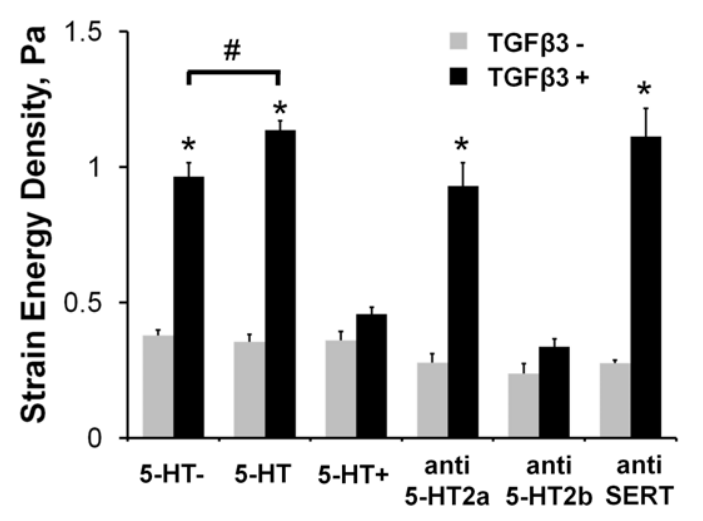

Figure 4. 5-HT signaling modulates TGF $\beta 3$ induced AV cushion stiffness. Physiological dosages of $5-\mathrm{HT}(470 \mathrm{nM}, 5-\mathrm{HT})$ exacerbated TGF $\beta 3$ stiffening, while elevated dosages ( $47 \mu \mathrm{M}, 5-H T+)$ eliminated it. Molecular inhibition of the 5-HT2a receptor (MDL100907 $10 \mathrm{nM}$, anti-5HT2a) and the serotonin transporter (Fluoxetine $10 \mu \mathrm{M}$, anti-SERT) did not affect TGF $\beta 3$ mediated biomechanical stiffening. Inhibition of the 5HT2b receptor (SB204741 $35 \mu \mathrm{M}$, anti-5-HT2b) however eliminated the stiffening effect of TGF $\beta 3$. mean \pm SEM, $n \geq 6,{ }^{*} p<0.0001$ t-test relative to control, $\# \mathrm{p}<0.05$ 2-way ANOVA with Tukey post-hoc test. doi:10.1371/journal.pone.0042527.g004

was over $50 \%$ lethal at $\mathrm{HH} 36$, but administration of the same dose of 5-HT at HH25 or HH31 did not result in further lethality or defect formation (data not shown). The only gross malformations observed were localized to the heart and chest wall. Approximately $42 \%$ (24/57) of affected embryos exhibited an ectopic heart which protruded through an incomplete chest wall closure (Figure $\mathrm{S} 6 \mathrm{~B})$. To confirm that interior defects resulted specifically from 5HT exposure and not secondarily from the ectopia, an experimental thoracotomy was performed to model the ectopic condition. We found no statistically significant occurrence of any cardiac defects with experimental ectopia, supporting that 5-HT was responsible for the cardiac defects observed. A ventricular septal defect (VSD or SVSD) occurred in $42 \%(24 / 57)$ of the defective embryos. Approximately 18\% (10/57) of the embryos exhibited double outlet right ventricle (DORV) defects. 5-HT administration also resulted in significantly enlarged atria with thinned walls in $35 \%(20 / 57)$ of the defective embryos (Table 1, Figure 6A). All of the embryos with DORV also exhibited highly stenotic or atretic atrioventricular (AV) valves (Figure 6B), with the normally muscular flap valve in the right AV canal appearing thin and fibrous like the left AV valve. Regardless of gross cardiac defect identified, the average $(0.144 \pm 0.009 \mathrm{~mm}$, mean $\pm \mathrm{SEM})$ and minimal $(0.080 \pm 0.007 \mathrm{~mm})$ thickness of the left AV septal leaflet was thinner in 5-HT treated embryos than controls $(0.191 \pm 0.009$ and $0.165 \pm 0.023 \mathrm{~mm}$ respectively, Figure $6 \mathrm{C})$. No differences were found in mural leaflet thickness, or in the length of either leaflet. The reduction in AV valve thickness with 5-HT treatment indicated an increase in tissue compaction, and may possibly be a recapitulation of the migratory/contractile phenotype observed ex vivo.

\section{Exogenous 5-HT increases AV cushion stiffness through TGF $\beta$ signaling in ovo}

Systemic 5-HT treatment at $\mathrm{HH} 17$ resulted in a statistically significant $1.4 \pm 0.2$ fold increase in $\mathrm{AV}$ cushion stiffness over control at stage HH25 (strain energy density of $0.43 \pm 0.06 \mathrm{~Pa}$ vs. $0.31 \pm 0.03 \mathrm{~Pa}, * \mathrm{p}<0.05$, Figure $7 \mathrm{~A}$ ). We next analyzed the mesenchymal gene expression patterns in this in ovo system. 5HT significantly upregulated TGF $\beta 3(1.7 \pm 0.1)$, $\alpha$ SMA (1.5 \pm 0.1$)$,
A
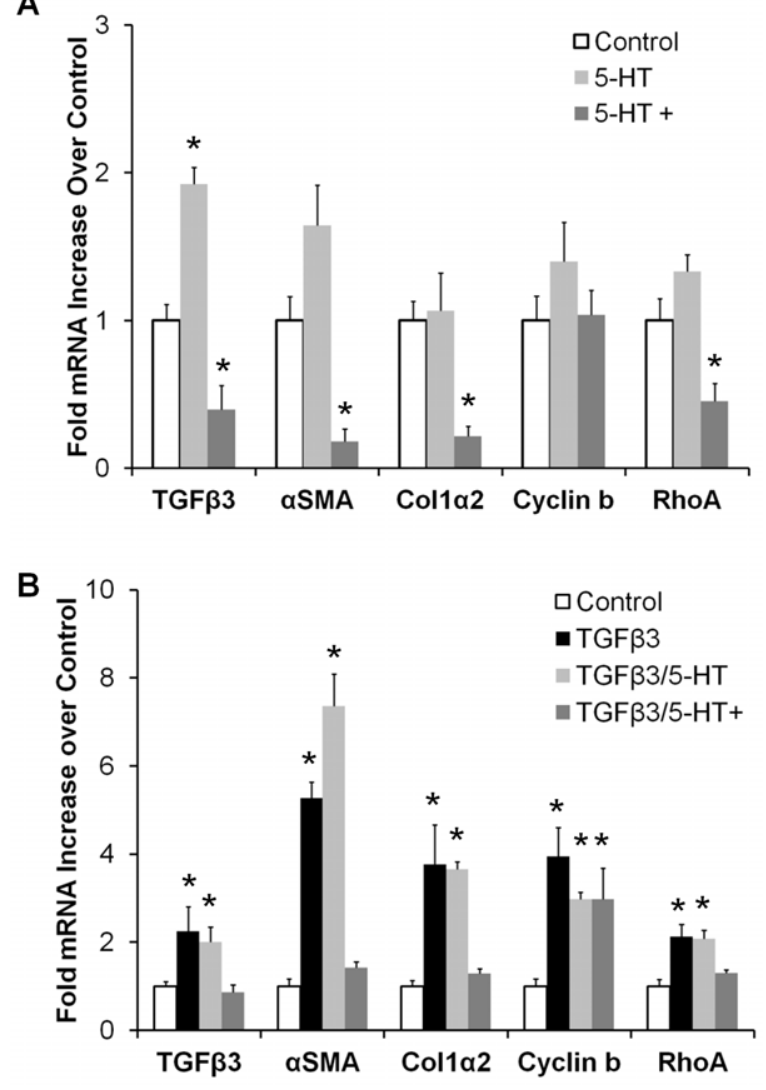

Figure 5. 5-HT treatment modulates TGF $\beta 3$ mediated gene expression. A) TGF $\beta 3$ mRNA transcripts increase with physiological 5HT (470 nM, 5-HT), but decrease at high dose (47 $\mu \mathrm{M}, 5-H T+)$. $\alpha \mathrm{SMA}$, RhoA, and col $1 \alpha 2$, were not affected by physiological 5 -HT dose, but were significantly downregulated with high 5-HT treatment. B) High 5$\mathrm{HT}$ treatment mitigates exogenous TGF $\beta 3$ induced contractile gene expression, while TGF $\beta 3$ induced proliferation was independent of 5-HT dose. mean \pm SEM, $n=3-5$ pooled samples of 8-10 cushions, ${ }^{*} \mathrm{p}<0.05$ via ANOVA comparisons with controls. doi:10.1371/journal.pone.0042527.g005

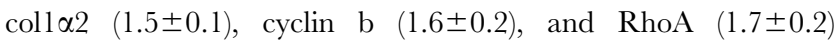
$\left({ }^{*} \mathrm{p}<0.05\right.$, Figure $\left.7 \mathrm{~B}\right)$. Interestingly, the TGF $\beta 3$ mRNA expression was comparable to that observed in the ex ovo organ culture treatment of TGF $\beta 3$ alone (2.2 \pm 0.6$), 5-\mathrm{HT}$ alone (1.9 \pm 0.1$)$, and TGF $\beta 3+5-H T$ (2.0 \pm 0.3$)$. $\alpha$ SMA and coll $\alpha 2$ mRNA were also upregulated in ovo with 5 -HT, but less than with direct TGF $\beta 3$ administration in ex vivo culture ( $\alpha \mathrm{SMA}-1.5$ vs 5.7 , RhoA -1.7 vs 2.1). The similar mRNA profiles of the candidate genes in both models suggested that 5 -HT also potentiates TGF $\beta$ signaling in AV cushions in ovo. To confirm that the 5-HT treatment was indeed modulating TGF $\beta$ signaling activity in ovo, we quantified nuclear pSmad2/3 expression in HH25 cushions with and without 5-HT treatment (Figure 8). 5-HT treatment increased the number of cell nuclei with localized pSmad2/3 expression $2.6 \pm 0.8$ fold over control embryos $(0.28 \pm 0.04$ vs. $0.11 \pm 0.03, \mathrm{p}<0.01)$. Together these results demonstrate that 5 -HT potentiates TGF $\beta$ signaling in $\mathrm{AV}$ cushions to control contractile differentiation, proliferation, and biomechanical remodeling.

\section{Discussion}

In this study we implemented a quantitative organ culture assay that simultaneously interrogated the contributions of cellular and 
Table 1. Cardiac Defect Summary of in ovo 5-HT Administration.

\begin{tabular}{|c|c|c|c|}
\hline & Control & Serotonin & Thoracotomy ${ }^{1}$ \\
\hline \# of embryos treated (HH17) & 35 & 133 & 107 \\
\hline \# of embryos survived (HH36) & 34 & 60 & 49 \\
\hline \# of defective embryos (HH36) & 0 & $57^{*}$ & 27 \\
\hline \multicolumn{4}{|c|}{ Summary of Defects Represented in Survival Groups ${ }^{2}$} \\
\hline Ectopic & - & $24^{*}$ & $25^{*}$ \\
\hline VSD & - & 5 & - \\
\hline SVSD & - & $19^{*}$ & 1 \\
\hline DILV & - & 3 & - \\
\hline DOLV & - & 1 & - \\
\hline DORV & - & $10^{*}$ & - \\
\hline Enlarged Atria & - & $20^{*}$ & 3 \\
\hline
\end{tabular}

${ }^{1}$ Thoracotomy control of ectopic heart condition was created by mechanically debriding the chest dermis and pericardium at $\mathrm{HH} 17$.

${ }^{2}$ Several embryos possessed more than one defect. VSD - ventricular septal defect; SVSD - stenotic VSD; DILV - double inlet left ventricle; DOLV - double outlet left ventricle; DORV - double outlet right ventricle. ${ }^{*} p<0.05$ Chi-Squared test.

doi:10.1371/journal.pone.0042527.t001

molecular signaling to drive cushion tissue-level remodeling and biomechanical strengthening. TGF 33 stimulated a 2.5 fold increase in biomechanical stiffness (Figure 1), generated in part by an increase in cell traction. This contractile phenotype is a common outcome of TGF $\beta$ signaling in post-natal valve tissue. For instance, porcine aortic valves express contractile marker $\alpha \mathrm{SMA}$ when stimulated by TGF $\beta 1$ in situ [58]. Porcine aortic valve interstitial cells (VICs) embedded in collagen gels expressed $\alpha \mathrm{SMA}$ in response to TGF $\beta 1$, and demonstrated significant gel compaction over untreated gels [59]. Similarly, TGF $\beta 3$ treated embryonic AV progenitors compacted collagen gels to $10 \%$ of initial area [23]. Yet in contrast to these reports, TGF $\beta 3$ induced contractility did not result in hyper-compacted AV cushions (Figure 2), but instead compacted less than controls. A key distinction between these two assays is that in vitro collagen gel cultures have much lower cell densities than our ex vivo system. The effect of proliferation on volume change is virtually undetectable in these gels, and cell traction dominates the compaction behavior. In native tissues, especially in the embryo, changes in cell proliferation and/or apoptosis have a significant impact on resulting tissue volume and apparent compaction. Hanging-drop culture of AV cushions enables precise control of the biochemical environment while maintaining the natural structural and cellular composition of the cushion. The lack of compaction with TGF $\beta 3$ treatment is therefore most likely due to a counterbalancing from increases in cell proliferation (Figure 3B) and ECM synthesis. This supports a mechanism of simultaneous tissue growth, matrix reorganization, and biomechanical stiffening during embryonic valve formation that is driven by a complex coordination of cell tractions, matrix synthesis, and cell proliferation. These findings underscore that embryonic valve mechanics, which is critical for proper valve function, cannot be inferred strictly from isolated compaction, proliferation, or matrix synthesis data, but is best measured directly.

The interplay of TGF $\beta 3$ and 5-HT signaling was most notably seen through the potentiation of TGF $\beta 3$ gene expression by 5 -HT
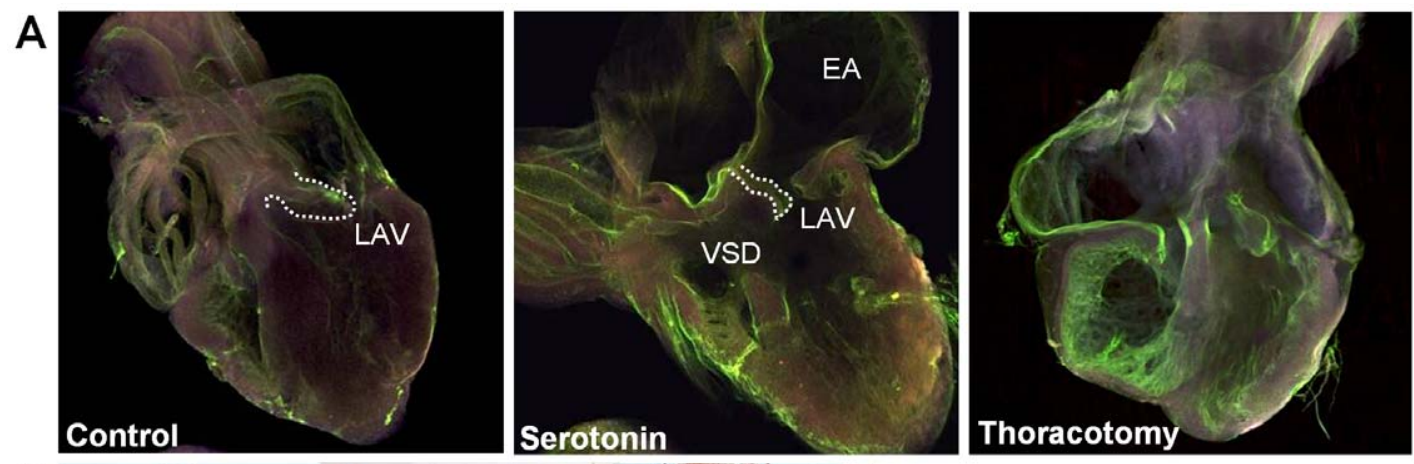

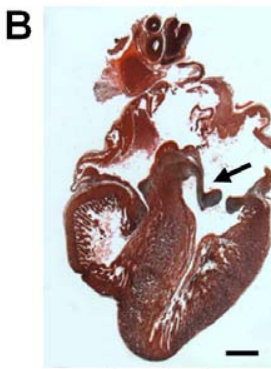

Control

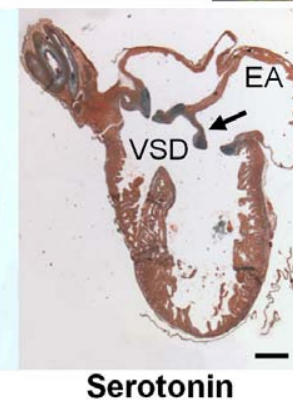

Serotonin

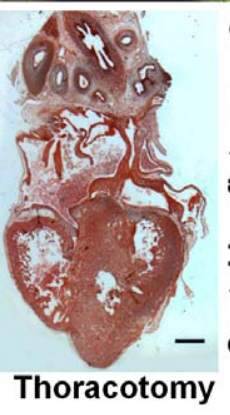

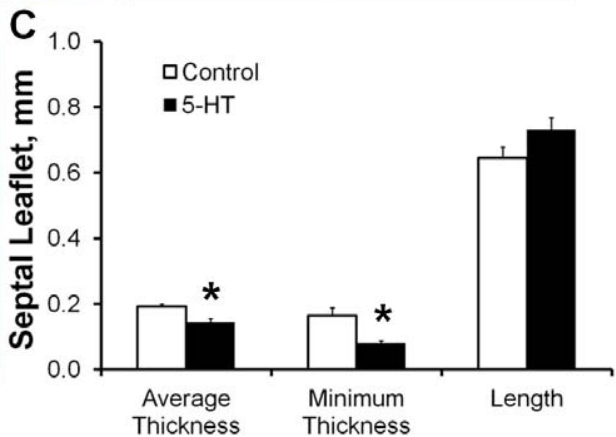

Figure 6. 5-HT administration in ovo induces cardiac defects. A) Representative virtual sections of control, 5-HT treated, and thoracotomy sham control hearts at HH36 via endopainting and confocal microscopy. B) Representative Movat's pentachrome stained sections of hearts with the same conditions. Prominent cardiac defects, including enlarged atria (EA) and ventricular septal defect (VSD), were associated with malformed and malfunctioning AV valves (arrows). $25 \times$, scale bar $=500 \mu \mathrm{m}$. C) Left septal leaflet average thickness and minimum thickness are both statistically thinner in 5-HT treated leaflets than control. mean \pm SEM, $n=3-6$ hearts per treatment, ${ }^{*} \mathrm{p}<0.05, \mathrm{t}$-test.

doi:10.1371/journal.pone.0042527.g006 
A

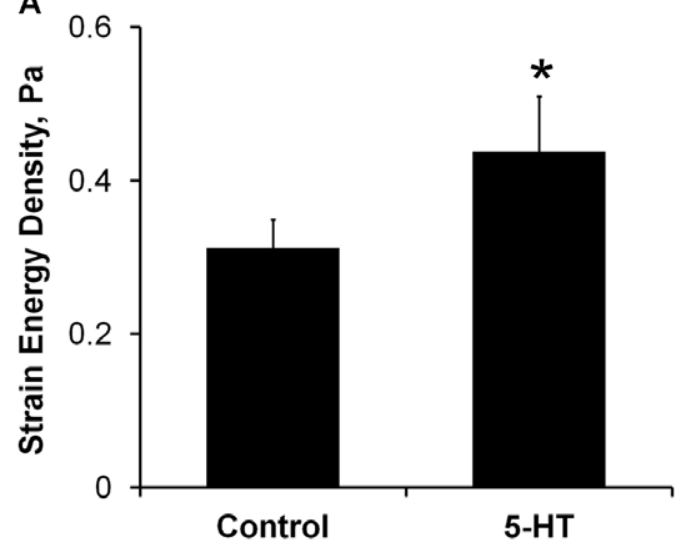

B 2.5 , in ovo

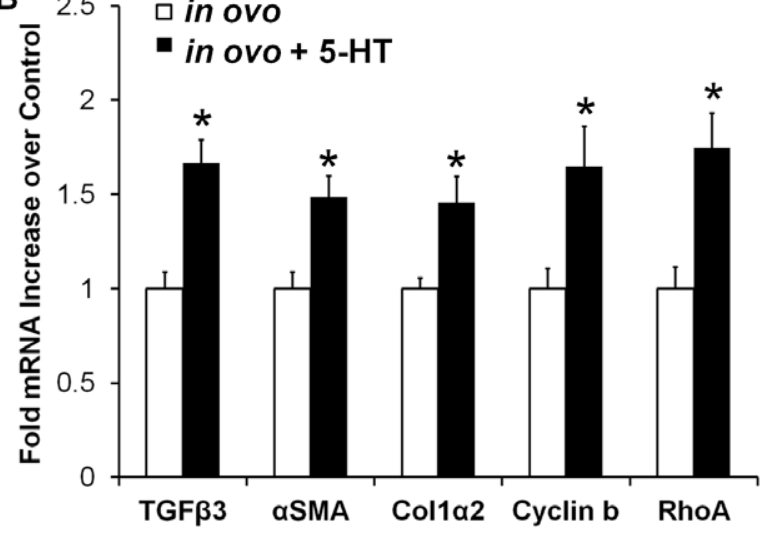

Figure 7. Exogenous 5-HT increases AV cushion stiffness and TGF $\boldsymbol{\beta}$ related remodeling genes in ovo. A) The strain energy density ( $\mathrm{Pa}$ ) of $\mathrm{HH} 25$ cushions increased 1.4 fold with systemic 5 -HT treatment in ovo, mean $\pm \mathrm{SEM}, \mathrm{n}=8-10$ cushion, ${ }^{*} \mathrm{p}<0.05$, t-test. B) Gene expression levels of $\mathrm{HH} 25 \mathrm{AV}$ cushions isolated from embryos treated with 5-HT at $\mathrm{HH} 17$ (48 hours). mean $\pm \mathrm{SEM}, \mathrm{n}=6-10$ samples, each of 8-10 pooled $\mathrm{HH} 25$ cushions, *p $<0.05$, t-test.

doi:10.1371/journal.pone.0042527.g007

dose (Figure 5). The physiological 5-HT concentration upregulated TGF 33 expression, while the high concentration downregulated expression. Upregulation of TGF $\beta$ expression by 5 -HT has been observed in several cardiac cells and tissues, though the molecular mechanism is still unclear. Adult aortic valve interstitial cells treated with 5 -HT have increased TGF $\beta 1$ activity, predominantly through the 5-HT2a receptor [25,60]. Neo-natal rat cardiac fibroblasts treated with 5-HT and 5-HT2a agonists upregulated $\alpha \mathrm{SMA}$ protein expression, which is a marker for fibroblast differentiation and a gene induced by TGF $\beta$ signaling [61]. Similarly, TGF $\beta 1$ and $\alpha$ SMA expression were elevated in SERT cre-lox KO mice hearts through heightened 5-HT2a signaling in late embryonic stage mice, purportedly due to excess 5-HT from SERT inhibition [43]. Other reports point to 5-HT2b as the key mechanism. 5-HT administration in adult rats increased 5 -HT2b mRNA expression in both aortic and mitral valves, demonstrating a positive response to 5-HT treatment [50]. SERT mRNA was downregulated in these valves denoting a negative response to elevated 5-HT, which our results also demonstrate (Figure S5B). The 5-HT2b receptor, TGF $\beta$ receptor type I and II, and the TGF $\beta$ latent binding protein were all more expressed in canine myxomatous mitral valves than normal valves, suggesting a
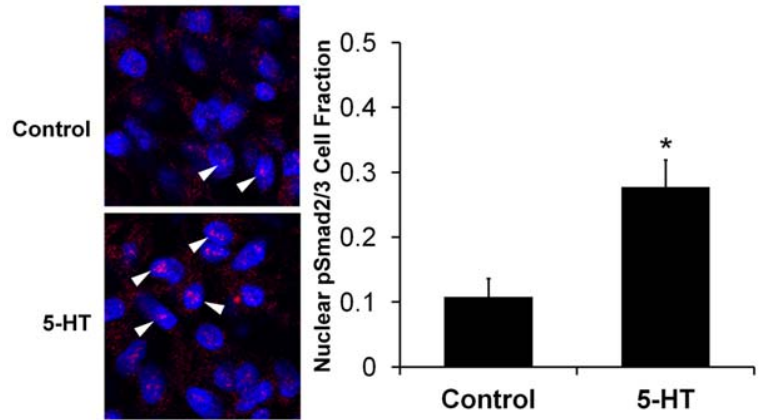

Figure 8. 5-HT increases AV cushion pSmad2/3 expression in ovo. A) Representative images of $\mathrm{pSmad} 2 / 3$ staining. Arrows indicate pSmad2/3 positive cells. Cell nuclei - blue, pSmad2/3 - red. B) Embryos treated with systemic $5-\mathrm{HT}$ at $\mathrm{HH} 17$ have increased $\mathrm{pSmad} 2 / 3$ expression at $\mathrm{HH} 25$ indicating elevated TGF $\beta$ signaling. $n=6$, mean \pm SEM ${ }^{*} \mathrm{p}<0.01$, t-test.

doi:10.1371/journal.pone.0042527.g008 coupling of these two pathways through 5-HT2b [26]. Long-term 5-HT treatment of rats generated valve-related echocardiographic and histology defects [62], but these defects did not occur in rats simultaneously treated with a 5-HT2b inhibitor [51]. This suggests that the 5-HT2b receptor may be a key pathway for cardiac and valve tissue remodeling. Cardiac fibroblast studies indicate that 5 HT upregulates TGF $\beta 1$ through a mutual transactivation of the epidermal growth factor (EGF) pathway and the 5-HT2b receptor $[45,63]$. Our results support a 5-HT2b dependant mechanism, as seen by 5 -HT2b inhibition effectively blocking TGF $\beta 3$ stiffening. The TGF $\beta$ stiffening effect was independent of 5-HT2a and SERT. Although TGF 33 upregulated TGM2 expression, 5-HT treatment mitigated this expression which suggests TGM2 activity does not contribute to the enhanced stiffening of TGF $\beta / 5-\mathrm{HT}$ signaling. High 5-HT also mitigated TGF 33 stiffening, which may be due to desensitization of the 5-HT2b receptor by sustained high 5-HT exposure. 5-HT increased pSmad2/3 phosphorylation in cushion mesenchyme in ovo. This suggests that 5-HT signaling through 5HT2b may interact with Smad2/3 signaling, but further studies are warranted to clarify potential roles of other intermediate or downstream targets.

In our in ovo model, systemic 5-HT elevation induced severe heart defects, including failure of the ventricular septum to close, ballooned atria, DORV, and hyper-contracted AV valves. Variations of these defects have been observed in other TGF $\beta$ and 5-HT related studies. VSDs are the most prevalent congenital heart defects observed, occurring in approximately $50 \%$ of all clinical cardiac malformations $[64,65]$. Selective serotonin uptake inhibitors (SSRI) taken during the first trimester of pregnancy were associated with a statistical increase in VSD prevalence in newborns [66]. Our data supports elevated extracellular 5-HT as a possible cause of this correlation. Removal of TGF $\beta$ secondary messenger Smad4 causes VSDs and other lethal congenital defects, which are presumed to be the consequence of decreased TGF $\beta$ signaling [67]. Yet removal of TGF $\beta$ inhibitory messenger Smad7 also generates VSDs [68], indicating that exacerbated TGF $\beta$ signaling can also generate significant cardiac defects. The dilated atria observed in our model are not explicitly reported in other 5-HT studies, suggesting the defect may result from secondary effects, such as altered hemodynamics from valve incompetence. For instance, enlarged atria have been induced in zebrafish embryos through mechanical obstruction of the AV 
canal [69]. Our avian model exhibited a small (18\%), but statistically significant, penetrance of DORV, which is a predominant congenital defect in TGF $\beta 2 \mathrm{KO}$ mice ( $87 \%$ penetrance) [17]. Collectively these defects highlight the morphogenetic potential of 5-HT in early cardiac development, and the similar spectrum of defects generated across 5-HT and TGF $\beta$ related animal models.

An interaction of TGF $\beta$ and 5-HT signaling was observed in ovo through the upregulation of TGF $\beta 3$ and contractile genes in the $\mathrm{AV}$ cushions (Figure 7B), the increase in pSmad2/3 expression (Figure 8), and the resulting thinned valve morphology (Figure 6C). While the pSmad2/3 and mRNA expression confirms that aspects of the ex vivo results occur in ovo, it is unclear whether elevated TGF $\beta$ signaling at $\mathrm{HH} 25$ is solely responsible for the thinned valve morphology observed at HH36. Hyperplastic and thickened AV valves occur in TGF $\beta 2 \mathrm{KO}(31 \%$ penetrance) $[17,70]$, and TGF $\beta$ latent binding protein $\mathrm{KO}$ (81\% penetrance) [57] animals, which supports this hypothesis. However, systemic 5-HT administration in adult rats generates thickened valves, with treatment duration dependent remodeling. Subcutaneous 5-HT injections for 7 days in adult rats produced thickened AV valves rich in GAGs [50], while 3-month treatment increased valve thickness, but consisted primarily of collagen [62]. Thickened, collagen-rich valves are also reported in adult SERT KO mice [71], and at late embryonic stage SERT KO pups [43]. Together these results indicate that elevated 5-HT signaling can instigate valvular remodeling in vivo, but changes in valve microstructure and morphology are clearly dependent on other factors such as treatment duration, specimen age, or secondary effects from accompanying congenital malformations. Altered hemodynamic loading can also generate defects, as evidenced through the serious malformations stimulated by mechanical perturbation [72,73]. Yet hemodynamic loading is simultaneously a consequence and stimulant of molecular signaling, interacting in a cyclical rather than a linear cause-effect manner. This again emphasizes the importance of direct assessment of mechanical stiffness, because it can distinguish the influence of these microstructure and microenvironment variations on valve performance.

Embryonic valve formation and maturation utilizes multiple TGF $\beta$ isoforms in spatially and temporally restricted ways that are also somewhat different between species $[16,18]$. We chose to focus on TGF $\beta 3$ over either TGF $\beta 1$ or TGF $\beta 2$ because of its principal role in cell invasion during chick cushion EMT [16], and confirmed increase in expression during post-EMT [23]. Our results establish a molecular mechanism for short-term (24 hours) TGF 33 stimulation on AV cushion biomechanical remodeling, but the effects of prolonged signaling on biomechanical and morphological changes remain unclear. This could be addressed with a combined in vivo/in vitro experimentation over more time points using a system like the approach presented here. The ex vivo culture system contains both endocardial and mesenchymal cells, but the lack of chick reactive antibodies prohibited the determination of cell specific responses. Our in ovo exogenous 5-HT administration model data complements existing data on genetic mutant animal models of TGF $\beta$ and 5-HT related signaling in cardiac development [17,74]. Future studies will need to investigate whether the serotonin effects of TGF $\beta 3$ change with TGF 33 dose.

In conclusion, tissue mechanics, cell phenotype, and molecular signaling all simultaneously direct and control tissue morphogenesis. Our results suggest that TGF $\beta$ is a potent stimulator of cushion stiffening, and that 5-HT is a key regulator of this stimulating effect. Connecting signaling networks with cell and tissue level responses will become increasingly important for understanding post-EMT valve remodeling and potentially other embryonic remodeling events. The quantitative experimental systems presented herein are an attractive approach for elucidating these multi-scale mechanisms and their downstream consequences.

\section{Supporting Information}

Table S1 RT-PGR Primer Sequences.

(TIF)

Figure S1 Minimal EGM organization in HH25 cushion supports use of an isotropic mechanical testing technique. A) Confocal image of a HH25 cushion with ECM labeled via 5-DTAF protein stain at $10 \times$ magnification. B) $40 \times$ magnification. Note the lack of matrix fiber density or preferential fiber orientation at this stage of development.

(TIF)

Figure S2 Gompaction-related stiffness control. A) Molecular inhibition of actin polymerization (Cytochalasin D, $1 \mu \mathrm{M}$ ) caused an $80-85 \%$ reduction in effective modulus. mean \pm SEM, $\mathrm{n} \geq 6 * \mathrm{p}<0.0001$, t-test $\mathbf{B})$ Cushion area increased with actin inhibition, resulting in a 3 fold decrease in measured compaction compared to control. Insets: Representative images of $\mathrm{AV}$ cushions before and after treatment, scale bar $=100 \mu \mathrm{m}$. mean \pm SEM, $\mathrm{n} \geq 12, * \mathrm{p}<0.0001, \mathrm{t}$-test.

(TIF)

Figure S3 TGF 33 -induced decrease in compaction was blocked through inhibition of Alk5 (SB431542, 2.6 $\mu \mathrm{M}$ ) or 5-HTR2b (SB204741 $35 \mu \mathrm{M}$, anti-5-HT2b). Neither 5HTR2a inhibitor (MDL100907 $10 \mathrm{nM}$, anti-5-HT2a) nor serotonin transporter inhibitor (Fluoxetine $10 \mu \mathrm{M}$, anti-SERT) affected TGF 33 compaction behavior. mean \pm SEM, $\mathrm{n} \geq 7,{ }^{*} \mathrm{p}<0.05$, $\mathrm{t}-$ test with respect to untreated controls.

(TIF)

Figure S4 TGFß3 and 5-HT stiffness generation is dependent on Alk5 signaling pathway. Strain energy density (Pa) of cushions treated with TGF $\beta 3(1 \mathrm{ng} / \mathrm{ml})$ only, TGF $\beta 3+\mathrm{Alk} 5$ inhibitor (SB431542, 2.6 $\mu \mathrm{M}$ anti-Alk5), TGF 33+5-HT (470 nM), and TGFß3+5-HT+anti-Alk5. mean \pm SEM, $n \geq 8$. Different letter pairings denotes statistically significant $\mathrm{p}<0.05$, 2-way ANOVA.

(TIF)

Figure S5 Intracellular 5-HT uptake is modulated by 5HT dose. A) 5-HT transporter (SERT) gene expression was downregulated via high 5-HT $(47 \mu \mathrm{M}, 5-H T+)$ dose, while transglutaminase 2 (TGM2) was not affected. The physiological dose of 5-HT (470 nM, 5-HT) had no effect on either SERT or TGM2 gene expression. B) TGF $\beta 3(1 \mathrm{ng} / \mathrm{ml})$ stimulated 4-fold increase in TGM2, which was mitigated by either doses of 5-HT. TGF 33 had no effect on SERT expression. mean \pm SEM, $n=3-$ $4,{ }^{*} \mathrm{p}<0.05$, t-test.

(TIF)

Figure S6 Gharacterization of in ovo 5-HT administration model. A) Plot of avian embryo viability as a function of time and 5-HT dose. 5-HT administration to the surface of HH17 chick embryos resulted in greater than $70 \%$ lethality at dosages above $0.75 \mathrm{mg}$. The majority of deaths occurred within 48 hours of incubation. Doses of $0.5 \mathrm{mg}$ and below were over $80 \%$ viable with virtually no morphological defects. Doses administered at later incubation times (Day 5, Day 7) did not result in lethality or defects by HH36 (data not shown). 5-HT administration at the predicted $50 \%$ lethality dose $(0.7 \mathrm{mg} / 100 \mu \mathrm{L})$ resulted in $55 \%$ lethality by Day 10. B) Representative image of ectopic heart 
(arrow) and unclosed chest (dashed line) observed with both 5-HT treatment and thoracotomy sham controls.

(TIF)

\section{Acknowledgments}

We thank Dr. Vladimir Mironov for helpful discussions on this work. We also thank Axon Medchem BV for the kind donation of reagent MDL100,907.

\section{References}

1. Butcher JT, Sedmera D, Guldberg RE, Markwald RR (2007) Quantitative volumetric analysis of cardiac morphogenesis assessed through micro-computed tomography. Dev Dyn 236(3): 802-809.

2. Hu N, Clark EB (1989) Hemodynamics of the stage 12 to stage 29 chick embryo. Circ Res 65(6): 1665-1670.

3. Keller BB, Hu N, Serrino PJ, Clark EB (1991) Ventricular pressure-area loop characteristics in the stage 16 to 24 chick embryo. Circ Res 68(1): 226-231.

4. Yalcin HC, Shekhar A, McQuinn TC, Butcher JT (2011) Hemodynamic patterning of the avian atrioventricular valve. Dev Dyn 240(1): 23-35.

5. Kruithof BP, Krawitz SA, Gaussin V (2007) Atrioventricular valve development during late embryonic and postnatal stages involves condensation and extracellular matrix remodeling. Dev Biol 302(1): 208-217.

6. Hinton RB,Jr, Lincoln J, Deutsch GH, Osinska H, Manning PB, et al. (2006) Extracellular matrix remodeling and organization in developing and diseased aortic valves. Circ Res 98(11): 1431-1438.

7. Person AD, Klewer SE, Runyan RB (2005) Cell biology of cardiac cushion development. Int Rev Cytol 243: 287-335.

8. Combs MD, Yutzey KE (2009) Heart valve development: Regulatory networks in development and disease. Circ Res 105(5): 408-421.

9. Butcher JT, Markwald RR (2007) Valvulogenesis: The moving target. Philos Trans R Soc Lond B Biol Sci 362(1484): 1489-1503.

10. Eisenberg LM, Markwald RR (1995) Molecular regulation of atrioventricular valvuloseptal morphogenesis. Circ Res 77(1): 1-6.

11. Attisano L, Wrana JL, Lopez-Casillas F, Massague J (1994) TGF-beta receptors and actions. Biochim Biophys Acta 1222(1): 71-80.

12. Massague J, Chen YG (2000) Controlling TGF-beta signaling. Genes Dev 14(6): $627-644$.

13. Shi Y, Massague J (2003) Mechanisms of TGF-beta signaling from cell membrane to the nucleus. Cell 113(6): 685-700.

14. Potts JD, Runyan RB (1989) Epithelial-mesenchymal cell transformation in the embryonic heart can be mediated, in part, by transforming growth factor beta. Dev Biol 134(2): 392-401.

15. Boyer AS, Ayerinskas II, Vincent EB, McKinney LA, Weeks DL, et al. (1999) TGFbeta2 and TGFbeta3 have separate and sequential activities during epithelial-mesenchymal cell transformation in the embryonic heart. Dev Biol 208(2): 530-545.

16. Camenisch TD, Molin DG, Person A, Runyan RB, Gittenberger-de Groot AC, et al. (2002) Temporal and distinct TGFbeta ligand requirements during mouse and avian endocardial cushion morphogenesis. Dev Biol 248(1): 170-181.

17. Bartram U, Molin DG, Wisse LJ, Mohamad A, Sanford LP, et al. (2001) Double-outlet right ventricle and overriding tricuspid valve reflect disturbances of looping, myocardialization, endocardial cushion differentiation, and apoptosis in TGF-beta(2)-knockout mice. Circulation 103(22): 2745-2752.

18. Azhar M, Runyan RB, Gard C, Sanford LP, Miller ML, et al. (2009) Ligandspecific function of transforming growth factor beta in epithelial-mesenchymal transition in heart development. Dev Dyn 238(2): 431-442.

19. Potts JD, Vincent EB, Runyan RB, Weeks DL (1992) Sense and antisense TGF beta 3 mRNA levels correlate with cardiac valve induction. Dev Dyn 193(4): 340-345.

20. Norris RA, Moreno-Rodriguez RA, Sugi Y, Hoffman S, Amos J, et al. (2008) Periostin regulates atrioventricular valve maturation. Dev Biol 316(2): 200-213.

21. Butcher JT, McQuinn TC, Sedmera D, Turner D, Markwald RR (2007) Transitions in early embryonic atrioventricular valvular function correspond with changes in cushion biomechanics that are predictable by tissue composition. Circ Res 100(10): 1503-1511.

22. Buskohl PR, Gould RA, Butcher JT (2012) Quantification of embryonic atrioventricular valve biomechanics during morphogenesis. J Biomech 45(5): 895-902.

23. Chiu YN, Norris RA, Mahler G, Recknagel A, Butcher JT (2010) Transforming growth factor beta, bone morphogenetic protein, and vascular endothelial growth factor mediate phenotype maturation and tissue remodeling by embryonic valve progenitor cells: Relevance for heart valve tissue engineering. Tissue Eng Part A 16(11): 3375-85.

24. Norris RA, Potts JD, Yost MJ, Junor L, Brooks T, et al. (2009) Periostin promotes a fibroblastic lineage pathway in atrioventricular valve progenitor cells. Dev Dyn 238(5): 1052-1063.

25. Jian B, Xu J, Connolly J, Savani RC, Narula N, et al. (2002) Serotonin mechanisms in heart valve disease I: Serotonin-induced up-regulation of transforming growth factor-betal via G-protein signal transduction in aortic valve interstitial cells. Am J Pathol 161(6): 2111-2121.

\section{Author Contributions}

Conceived and designed the experiments: PRB RPT JTB. Performed the experiments: PRB MLS RTP JTB. Analyzed the data: PRB MLS JTB. Contributed reagents/materials/analysis tools: JTB RPT. Wrote the paper: PRB JTB.

26. Disatian S, Orton EC (2009) Autocrine serotonin and transforming growth factor beta 1 signaling mediates spontaneous myxomatous mitral valve disease. J Heart Valve Dis 18(1): 44-51.

27. El-Hamamsy I, Balachandran K, Yacoub MH, Stevens LM, Sarathchandra P, et al. (2009) Endothelium-dependent regulation of the mechanical properties of aortic valve cusps. J Am Coll Cardiol 53(16): 1448-1455.

28. Warnock JN, Gamez CA, Metzler SA, Chen J, Elder SH, et al. (2010) Vasoactive agents alter the biomechanical properties of aortic heart valve leaflets in a time-dependent manner. J Heart Valve Dis 19(1): 86-95; discussion 96.

29. Roth BL, Willins DL, Kristiansen K, Kroeze WK (1998) 5-Hydroxytryptamine2-family receptors (5-hydroxytryptamine2A, 5-hydroxytryptamine2B, 5hydroxytryptamine2C): Where structure meets function. Pharmacol Ther 79(3): 231-257.

30. Balachandran K, Hussain S, Yap CH, Padala M, Chester AH, et al. (2011) Elevated cyclic stretch and serotonin result in altered aortic valve remodeling via a mechanosensitive 5-HT(2A) receptor-dependent pathway. Cardiovasc Pathol.

31. Hafizi S, Taylor PM, Chester AH, Allen SP, Yacoub MH (2000) Mitogenic and secretory responses of human valve interstitial cells to vasoactive agents. J Heart Valve Dis 9(3): 454-458.

32. Oyama MA, Levy RJ (2010) Insights into serotonin signaling mechanisms associated with canine degenerative mitral valve disease. J Vet Intern Med 24(1): 27-36.

33. Lauder JM (1988) Neurotransmitters as morphogens. Prog Brain Res 73: 365387.

34. Levin M, Buznikov GA, Lauder JM (2006) Of minds and embryos: Left-right asymmetry and the serotonergic controls of pre-neural morphogenesis. Dev Neurosci 28(3): 171-185.

35. Moiseiwitsch JR, Lauder JM (1995) Serotonin regulates mouse cranial neural crest migration. Proc Natl Acad Sci U S A 92(16): 7182-7186.

36. Fukumoto T, Blakely R, Levin M (2005) Serotonin transporter function is an early step in left-right patterning in chick and frog embryos. Dev Neurosci 27(6): 349-363.

37. Sadler TW (2011) Selective serotonin reuptake inhibitors (SSRIs) and heart defects: Potential mechanisms for the observed associations. Reprod Toxicol 32(4): 484-9.

38. Lauder JM, Wilkie MB, Wu C, Singh S (2000) Expression of 5-HT(2A), 5$\mathrm{HT}(2 \mathrm{~B})$ and 5-HT(2C) receptors in the mouse embryo. Int J Dev Neurosci 18(7): 653-662.

39. Choi DS, Ward SJ, Messaddeq N, Launay JM, Maroteaux L (1997) 5-HT2B receptor-mediated serotonin morphogenetic functions in mouse cranial neural crest and myocardiac cells. Development 124(9): 1745-1755.

40. Millan FA, Denhez F, Kondaiah P, Akhurst RJ (1991) Embryonic gene expression patterns of TGF beta 1, beta 2 and beta 3 suggest different developmental functions in vivo. Development 111(1): 131-143.

41. Yavarone MS, Shuey DL, Tamir H, Sadler TW, Lauder JM (1993) Serotonin and cardiac morphogenesis in the mouse embryo. Teratology 47(6): 573-584.

42. Nakajima Y, Miyazono K, Kato M, Takase M, Yamagishi T, et al. (1997) Extracellular fibrillar structure of latent TGF beta binding protein-1: Role in TGF beta-dependent endothelial-mesenchymal transformation during endocardial cushion tissue formation in mouse embryonic heart. J Cell Biol 136(1): 193204.

43. Pavone LM, Spina A, Rea S, Santoro D, Mastellone V, et al. (2009) Serotonin transporter gene deficiency is associated with sudden death of newborn mice through activation of TGF-betal signalling. J Mol Cell Cardiol 47(5): 691-697.

44. Watts SW, Priestley JR, Thompson JM (2009) Serotonylation of vascular proteins important to contraction. PLoS One 4(5): e5682.

45. Jaffre F, Bonnin P, Callebert J, Debbabi H, Setola V, et al. (2009) Serotonin and angiotensin receptors in cardiac fibroblasts coregulate adrenergic-dependent cardiac hypertrophy. Circ Res 104(1): 113-123.

46. Aoki T, Ohashi T, Matsumoto T, Sato M (1997) The pipette aspiration applied to the local stiffness measurement of soft tissues. Ann Biomed Eng 25(3): 581587.

47. Zhao R, Sider KL, Simmons CA (2011) Measurement of layer-specific mechanical properties in multilayered biomaterials by micropipette aspiration. Acta Biomater 7(3): 1220-1227.

48. Fung YC (1991) What are the residual stresses doing in our blood vessels? Ann Biomed Eng 19(3): 237-249.

49. Bookout AL, Mangelsdorf DJ (2003) Quantitative real-time PCR protocol for analysis of nuclear receptor signaling pathways. Nucl Recept Signal 1: e012. 
50. Elangbam CS, Job LE, Zadrozny LM, Barton JC, Yoon LW, et al. (2008) 5hydroxytryptamine (5HT)-induced valvulopathy: Compositional valvular alterations are associated with 5HT2B receptor and 5HT transporter transcript changes in sprague-dawley rats. Exp Toxicol Pathol 60(4-5): 253-262.

51. Hauso O, Gustafsson BI, Loennechen JP, Stunes AK, Nordrum I, et al. (2007) Long-term serotonin effects in the rat are prevented by terguride. Regul Pept 143(1-3): 39-46.

52. Miller CE, Thompson RP, Bigelow MR, Gittinger G, Trusk TC, et al. (2005) Confocal imaging of the embryonic heart: How deep? Microsc Microanal 11(3): 216-223.

53. Kern CB, Norris RA, Thompson RP, Argraves WS, Fairey SE, et al. (2007) Versican proteolysis mediates myocardial regression during outflow tract development. Dev Dyn 236(3): 671-683.

54. Inman GJ, Nicolas FJ, Callahan JF, Harling JD, Gaster LM, et al. (2002) SB431542 is a potent and specific inhibitor of transforming growth factor-beta superfamily type I activin receptor-like kinase (ALK) receptors ALK4, ALK5, and ALK7. Mol Pharmacol 62(1): 65-74.

55. Guilluy C, Rolli-Derkinderen M, Tharaux PL, Melino G, Pacaud P, et al. (2007) Transglutaminase-dependent RhoA activation and depletion by serotonin in vascular smooth muscle cells. J Biol Chem 282(5): 2918-2928.

56. Liu Y, Wei L, Laskin DL, Fanburg BL (2010) Role of protein transamidation in serotonin-induced proliferation and migration of pulmonary artery smooth muscle cells. Am J Respir Cell Mol Biol 44(4): 548-55.

57. Todorovic V, Finnegan E, Freyer L, Zilberberg L, Ota M, et al. (2011) Long form of latent TGF-beta binding protein 1 (LtbplL) regulates cardiac valve development. Dev Dyn 240(1): 176-187.

58. Merryman WD, Lukoff HD, Long RA, Engelmayr GC Jr, Hopkins RA, et al. (2007) Synergistic effects of cyclic tension and transforming growth factor-betal on the aortic valve myofibroblast. Cardiovasc Pathol 16(5): 268-276.

59. Walker GA, Masters KS, Shah DN, Anseth KS, Leinwand LA (2004) Valvular myofibroblast activation by transforming growth factor-beta: Implications for pathological extracellular matrix remodeling in heart valve disease. Circ Res 95(3): 253-260.

60. Xu J, Jian B, Chu R, Lu Z, Li Q et al. (2002) Serotonin mechanisms in heart valve disease II: The 5-HT2 receptor and its signaling pathway in aortic valve interstitial cells. Am J Pathol 161(6): 2209-2218.

61. Yabanoglu S, Akkiki M, Seguelas MH, Mialet-Perez J, Parini A, et al. (2009) Platelet derived serotonin drives the activation of rat cardiac fibroblasts by 5HT2A receptors. J Mol Cell Cardiol 46(4): 518-525.
62. Gustafsson BI, Tommeras K, Nordrum I, Loennechen JP, Brunsvik A, et al. (2005) Long-term serotonin administration induces heart valve disease in rats. Circulation 111(12): 1517-1522.

63. Monassier L, Laplante MA, Ayadi T, Doly S, Maroteaux L (2010) Contribution of gene-modified mice and rats to our understanding of the cardiovascular pharmacology of serotonin. Pharmacol Ther 128(3): 559-567.

64. Hoffman JI, Kaplan S (2002) The incidence of congenital heart disease. J Am Coll Cardiol 39(12): 1890-1900.

65. Reller MD, Strickland MJ, Riehle-Colarusso T, Mahle WT, Correa A (2008) Prevalence of congenital heart defects in metropolitan atlanta, 1998-2005. J Pediatr 153(6): 807-813.

66. Merlob P, Birk E, Sirota L, Linder N, Berant M, et al. (2009) Are selective serotonin reuptake inhibitors cardiac teratogens? echocardiographic screening of newborns with persistent heart murmur. Birth Defects Res A Clin Mol Teratol 85(10): 837-841.

67. Qi X, Yang G, Yang L, Lan Y, Weng T, et al. (2007) Essential role of Smad4 in maintaining cardiomyocyte proliferation during murine embryonic heart development. Dev Biol 311(1): 136-146.

68. Chen Q Chen H, Zheng D, Kuang C, Fang H, et al. (2009) Smad7 is required for the development and function of the heart. J Biol Chem 284(1): 292-300.

69. Hove JR, Koster RW, Forouhar AS, Acevedo-Bolton G, Fraser SE, et al. (2003) Intracardiac fluid forces are an essential epigenetic factor for embryonic cardiogenesis. Nature 421(6919): 172-177.

70. Azhar M, Brown K, Gard C, Chen H, Rajan S, et al. (2011) Transforming growth factor Beta2 is required for valve remodeling during heart development. Dev Dyn 240(9): 2127-2141.

71. Mekontso-Dessap A, Brouri F, Pascal O, Lechat P, Hanoun N, et al. (2006) Deficiency of the 5-hydroxytryptamine transporter gene leads to cardiac fibrosis and valvulopathy in mice. Circulation 113(1): 81-89.

72. Yalcin HC, Shekhar A, Nishimura N, Rane AA, Schaffer CB, et al. (2010) Twophoton microscopy guided femtosecond-laser photoablation of avian cardiogenesis: Noninvasive creation of localized heart defects. Am J Physiol Heart Circ Physiol.

73. Sedmera D, Pexieder T, Rychterova V, Hu N, Clark EB (1999) Remodeling of chick embryonic ventricular myoarchitecture under experimentally changed loading conditions. Anat Rec 254(2): 238-252.

74. Nebigil CG, Hickel P, Messaddeq N, Vonesch JL, Douchet MP, et al. (2001) Ablation of serotonin $5-\mathrm{HT}(2 \mathrm{~B})$ receptors in mice leads to abnormal cardiac structure and function. Circulation 103(24): 2973-2979. 